\title{
Genetic architecture of resistance to aphids and mites in a willow hybrid system
}

\author{
ME Czesak, MJ Knee, RG Gale, SD Bodach and RS Fritz \\ Department of Biology, Vassar College, Poughkeepsie, NY 12604, USA
}

\begin{abstract}
Hybrid plants often differ in resistance to arthropods compared to the parental species from which they are derived. To better understand the relative contribution of genetic effects in influencing plant resistance to arthropods, we examined the genetic architecture of resistance in a willow hybrid system, Salix eriocephala, S. sericea, and their interspecific hybrids. Resistance to two arthropods, a willow leaf aphid (Chaitophorus sp.: Aphididae) and an eriophyoid mite (Aculops tetanothrix: Eriophyidae), were compared because resistance to different herbivores may be controlled by different traits and influenced by different genetic effects. We found additive and nonadditive genetic effects to be important in explaining the difference between willow species
\end{abstract}

in resistance to aphids and mites. $F_{2}$ hybrids exhibited low resistance to aphids, suggesting breakdown of favourable epistatic interactions that confer resistance. $F_{2}$ hybrids, however, exhibited high resistance to mites, suggesting either the breakdown of interactions that affect traits used by mites in host location or the creation of favourable epistatic interactions. This study demonstrates the potential role of herbivores in affecting plant genetic structure, such that selection by herbivores can potentially lead to the creation of gene interactions that influence host resistance traits or host recognition traits used by the herbivore.

Heredity (2004) 93, 619-626. doi:10.1038/sj.hdy.6800587

Published online 8 September 2004

Keywords: backcross; dominance; epistasis; herbivory; susceptibility

\section{Introduction}

Hybridisation is a common phenomenon among plant species and some animal species. One viewpoint is that hybridisation is a maladaptive process because hybrids often have reduced fertility or viability, increased frequency of developmental abnormalities, or increased susceptibility to disease or parasites relative to the parental species from which they are derived (reviewed in Arnold and Hodges, 1995; Arnold, 1997; Rieseberg, 1997; Burke and Arnold, 2001). Alternatively, hybridisation can be a creative process that generates genetic variation by creating novel combinations of genes via recombination or by transferring genes among parental species via introgression (reviewed in Arnold and Hodges, 1995; Arnold, 1997; Rieseberg, 1997; Burke and Arnold, 2001).

Hybrid plants often differ from their parental species in resistance to herbivores (eg, Wimp and Whitham, 2001). The abundance and/or diversity of herbivores can be higher on hybrids relative to parental species, thereby reducing hybrid fitness and perhaps limiting hybrid abundance and geographic range (Whitham, 1989; Dungey et al, 2000; reviewed in Fritz et al, 1999). Conversely, herbivore abundance and/or diversity can be low on hybrids compared to one or both parental species (reviewed in Fritz et al, 1999).

Several quantitative genetic hypotheses have been proposed to explain hybrid resistance relative to the parental species (Fritz, 1999). Additive inheritance of

Correspondence: ME Czesak, Department of Biology, Vassar College, Poughkeepsie, NY 12604, USA. E-mail: maczesak@vassar.edu

Received 24 October 2003; accepted 26 July 2004; published online 8 September 2004 resistance results in hybrids that have intermediate resistance between the two parental species, whereas dominance of some resistance alleles or interactions among resistance genes can result in hybrid resistance that is more similar to one of the parental species (reviewed in Fritz, 1999; Fritz et al, 1999). Hybrids can also have superior resistance than either parental species (hybrid resistance hypothesis; reviewed in Fritz, 1999; Fritz et al, 1999), which for other traits has been attributed to overdominance of alleles, masking of deleterious alleles (Fenster and Galloway, 2000), or favourable epistatic interactions among loci (Lynch, 1991). Hybrids can also have inferior resistance than either parental species (hybrid susceptibility hypothesis), which can be due to disruptions in interactions among loci (coadapted gene complexes, Waser, 1993 or local adaptation, Templeton, 1986), unfavourable epistatic interactions among loci, or underdominance (Schierup and Christiansen, 1996) as found for other traits. Hybrid resistance can also not differ from that of the parental species. Support for each of these hypotheses depends on the study system and the type of study (ie, field census, common garden, laboratory), with most studies supporting the hypothesis of no difference $(29 \%)$, followed by the additive (22\%), dominance of hybrid susceptibility $(21 \%)$, and hybrid susceptibility hypotheses (17\%; from Table 2 in Fritz et al, 1999).

Detailed genetic analysis of traits that affect plant fitness in hybrid systems ultimately supplements our understanding of the processes of genetic differentiation, local adaptation and speciation (Burke and Arnold, 2001) and is necessary for the prediction of hybrid fitness in breeding and conservation programmes (Linder et al, 1998). The genetic architecture of traits has been most 
thoroughly studied in horticultural and agricultural species with the aim of detecting the additive or additive $\times$ additive genetic effects necessary for successful artificial selection (reviewed in Lynch and Walsh, 1998). Yet, for many traits, nonadditive genetic effects contribute to interpopulational or interspecific differences among trait means (eg, Armbruster et al, 1997) and, if these nonadditive genetic effects occur within each population or species, can result in evolutionary trajectories that are difficult to predict or can result in asymmetrical responses to selection (Merilä and Sheldon, 1999; Galloway and Fenster, 2001).

Few studies have attempted to detect nonadditive genetic effects on plant resistance to herbivores using hybrids. Using a Salix eriocephala-S. sericea hybrid system, Fritz et al (2003) examined the genetic architecture of plant resistance to arthropods that existed within a community and found that additive and nonadditive genetic effects were important to explain the difference in resistance between the two species. Here, we examined the relative importance of additive and nonadditive genetic effects on differences between $S$. eriocephala and $S$. sericea in resistance to two arthropods, a willow leaf aphid (Chaitophorus sp.: Aphididae) and a mite (Aculops tetanothrix: Eriophyidae). The current study differs from Fritz et al (2003) in that the plants were kept free of herbivores other than the two species studied, and thus interspecific interactions with other herbivore species could not potentially affect resistance measurements (ie, aphid survival, aphid reproduction, and total number of mite galls). We document the potential of herbivores to affect plant evolution, such that selection by herbivores can lead to the creation of gene interactions that influence plant resistance traits or host recognition traits used by herbivores.

\section{Methods}

\section{Natural history of study organisms}

Willows: S. eriocephala and S. sericea are shrubs that occur in swampy habitats and along streams in the eastern US and Canada (Argus, 1986). These two species differ in various traits that can potentially affect resistance to herbivores. S. eriocephala has glabrous leaves that contain high concentrations of condensed tannins (Orians and Fritz, 1995). S. sericea has leaves that are densely covered with trichomes on the lower surface and contain high concentrations of phenolic glycosides (especially salicortin) and low concentrations of condensed tannins (Orians and Fritz, 1995). Throughout their geographic range, $S$. eriocephala and $S$. sericea hybridise and co-occur with their hybrids (Argus 1974, 1986; Mosseler and Papadopol, 1989). $F_{1}$ hybrids have leaves with a dense covering of trichomes on the lower surface (S. sericea trait) and concentrations of condensed tannins and phenolic glycosides that are intermediate between the concentrations of the two parental species (Orians and Fritz, 1995).

Aphids: In the spring, wingless fundatrix (ie, foundress) Chaitophorus sp. females hatch from sexually produced eggs and parthenogenetically produce wingless females. Many parthenogenetic generations are produced throughout the season. Sexual females and males are produced when the photoperiod shortens and temperature drops; the females mate to produce overwintering eggs. Aphids can be particularly devastating to plants because this parthenogenetic lifecycle allows for quick population growth and also because they consume great quantities of phloem to meet their amino-acid requirements (Dixon, 1985).

Mites: Aculops tetanothrix passes through a larval and nymph stage before reaching maturity, with a resting stage between the two immature stages. Females that are produced in the autumn mate with males and overwinter in sheltered crevices on the plant (eg, under bud scales). In the spring, these females stimulate gall formation and lay many eggs in the gall, which hatch in a few days into females and males. Several generations occur in the summer before production of overwintering females (Manson and Oldfield, 1996).

\section{Experimental design}

Willow, aphid, and mite populations were obtained from a site located in central New York, USA (Milford, NY, USA; $\left.42^{\circ} 31^{\prime} \mathrm{N}, 75^{\circ} 41^{\prime} \mathrm{W}\right)$. Pure species were previously identified using RAPD markers (Hardig et al, 2000). Families of $S$. eriocephala, S. sericea, and their interspecific $\mathrm{F}_{1}, \mathrm{~F}_{2}$, and backcross hybrids were created in April 1998 through controlled crosses $(n=6$ families for $S$. eriocephala; $n=5$ families each for $S$. sericea, $F_{1}$ hybrids, $F_{2}$ hybrids, and backcrosses to $S$. eriocephala; $n=4$ families for backcrosses to $S$. sericea). To create $F_{1}$ hybrids, a female $S$. sericea was crossed with a male $S$. eriocephala. The reciprocal cross does not produce viable seeds. $F_{2}$ hybrids were created by crossing an unrelated female and male $\mathrm{F}_{1}$ hybrid. Backcrosses to each parental species were created by crossing a female $F_{1}$ hybrid to either a male $S$. eriocephala or a male $S$. sericea.

To create crosses, mesh bags were placed over branches of female catkins before the stigmas were exposed. Pollen from male catkins was brushed onto female catkins, and the mesh bag was replaced over the female catkins until seeds matured. Seeds were collected and planted into trays containing moist potting mix (Metromix 360 ${ }^{\mathbb{R}}$ ) in late May 1998 and kept in an openended greenhouse at the field site. Seedlings were kept moist and fertilized when necessary (Peter's 20-20-20 ${ }^{\circledR}$, 20:20:20 N:P:K). After 2-3 weeks of growth, seedlings were transplanted into individual cells with potting mix $(600 \mathrm{ml})$ and kept moist and fertilized when necessary. In August 1998, seedlings were transplanted into 1.81 pots containing a 3:1:1 mixture of top soil, peat moss, and vermiculite and $13 \mathrm{~g}$ of slow-releasing fertilizer (Osmo$\left.\operatorname{cote}^{\mathbb{R}} ; 10: 10: 10 \mathrm{~N}: \mathrm{P}: \mathrm{K}\right)$ and moved to a fenced plot at the field site. In the spring of 1999, plants were transplanted into 3.71 pots with $13 \mathrm{~g}$ of slow-releasing fertilizer. Fertilizer was also applied during the spring of 2000 and 2001. During the summers of 1999-2001, plants were sprayed for arthropod herbivores and rust fungus as necessary.

To create ramets of each willow genotype, seven cuttings were taken from branches in early March 2002. Cuttings were kept in water and stored at $3^{\circ} \mathrm{C}$ for 2 weeks and then planted into $300 \mathrm{ml}$ pots with potting soil (Metromix $360^{\mathbb{R}}$ ). Cuttings were grown in a greenhouse for 8 weeks. In late May 2002, cuttings were transplanted to 3.71 pots with a 3:1:1 mixture of topsoil, peat moss, 
and vermiculite and $13 \mathrm{~g}$ of slow-releasing fertilizer. One or two ramets of each willow genotype were randomly placed in an open-ended greenhouse covered with $30 \%$ shade cloth (aphid-resistance experiment), and the rest of the ramets per willow genotype (1-5 ramets) were placed in a plot adjacent to the greenhouse (mite-resistance experiment). Plants were grown for 3 weeks before the experiments (see below).

In total, there were 165 different genotypes from six genetic classes (parental species and hybrids with four to six families within each genetic class). From these 165 genotypes, between three and seven ramets were grown for a total of 711 plants. Of these 711 plants, 292 were used to test resistance to aphids (one or two ramets per willow genotype, mean $\pm S E=1.77 \pm 0.03$ ), while 419 were used to test resistance to mites (one to five different ramets per willow genotype, mean $\pm S E=2.52 \pm 0.08$ ).

Aphids: Two colonies of Chaitophorus sp. aphids were collected in late May 2002 from individual trees of $S$. sericea at the field site. Each colony contained a single wingless female and several nymphs and was reared separately on $S$. sericea plants for 7 weeks in a greenhouse under ambient light and temperature conditions. The plants used for rearing aphids were grown from cuttings, as described previously. We also attempted to rear aphids on $S$. eriocephala plants, but aphids did not survive. After 7 weeks, each aphid colony contained several hundred individuals, including mostly wingless females and nymphs and a few winged females.

There were two replicates of the experiment, such that aphids from one colony were tested on one ramet of each of the 165 willow genotypes, and aphids from a second colony were tested on another ramet of these genotypes. In mid-July 2002, one second-instar nymph was placed on a fully expanded leaf on each plant near the actively growing apical meristem. This stage of nymph was chosen because each aphid colony had approximately 200 aphids of this stage, which was required to place aphids of the same stage on the plants. Ventilated cages made from $5.5 \mathrm{~cm}$ Petri dishes were used to contain the aphid on each leaf. Aphid population growth on a subsample of plants was monitored every week to choose an appropriate time to collect data on aphid population growth. Since aphids were restricted to one leaf, we aimed to record aphid reproduction as their populations were increasing, but before a decline in population growth occurred. After 2 weeks, aphids were scored as either having survived or died. The number of winged females, wingless females, and nymphs were counted on each leaf.

Mites: Mite presence on the willows was not manipulated. The number of mite galls was counted on the first four fully expanded leaves of each plant. Mite galls were divided into two categories - large and small. Large galls were distinguished by a protrusion and visibility on both sides of the leaf, whereas small galls were only visible on one side of a leaf and did not fully develop. Galls were measured (average diameter from measurements in two directions, in $\mathrm{mm}$ ) and dissected, and the number of mites and eggs was counted per gall (immature and adult stages were classified together). The relationship between gall size and number of mites per gall was estimated. Only galls on leaves of S. eriocephala,
$F_{1}$ hybrids, and backcrosses to $S$. eriocephala were dissected because these genetic classes were most heavily attacked (see Results).

Relationship between aphid and mite resistance: We manually removed other herbivores from the plants. We could not keep mites off the plants used to test for resistance to aphids without applying a miticide with unknown effects on aphid survival and/or reproduction. Thus, to test for resistance to aphids, we used the first fully expanded leaf that did not have mite galls, and this leaf was always within four leaves of the apical meristem. The downside of this is that aphid survival and/or reproduction may be negatively affected by the presence of mite galls on a plant (although not on the same leaf), but the upside is that the relationship between aphid survival and the presence or absence of mite galls on the same plant can be estimated.

\section{Analysis}

Since the total number of aphids and mite galls may depend on plant size, these measures of resistance were also analysed per unit of plant height $(\mathrm{cm})$, and length and width of the first fully expanded leaf $(\mathrm{mm})$. The total numbers of aphids and mite galls were averaged between ramets from the same willow genotype and then averaged among genotypes from the same family. Aphid survival was averaged among genotypes from the same family within each replicate.

Aphid survival: Survival of each aphid nymph was classified as either ' 0 ' if it died or ' 1 ' if it survived. A Kruskal-Wallis test was used to test for an effect of willow genetic class on mean aphid survival within each replicate, and means were contrasted with the predicted means (SAS PROC GLM on ranked data, with CONTRAST statements; SAS Institute, 1985). If inheritance is purely additive, $F_{1}$ and $F_{2}$ hybrid means are predicted to be intermediate between the $S$. eriocephala mean and $S$. sericea mean, and backcross means are predicted to lie between this intermediate mean and either the $S$. eriocephala mean or S. sericea mean (depending on the parental species from which the backcross was created).

Aphid reproduction: Of the aphids that survived, the number of offspring produced was counted after 2 weeks. Since the total number of aphid offspring was counted only for surviving aphids (ie, zeros were not entered for aphids that died), there were some willow families with missing values for one replicate or the other. For this reason, data from the two replicates were pooled (replicate effect: $F_{1,35}=0.00, P=0.962$, replicate* ${ }^{*}$ enetic class $F_{5,35}=0.42, P=0.832$, analysed using SAS PROC GLM, SAS Institute, 1985). A Kruskal-Wallis test was used to test for an effect of willow genetic class on mean aphid reproduction, and means were contrasted with predicted means as described above.

Mite resistance: A Kruskal-Wallis test was used to test for an effect of willow genetic class on mean total number of mite galls, and means were contrasted with predicted means as described above. The relationship between gall size (average diameter, in $\mathrm{mm}$ ) and the 
number of mites inside the gall was analysed separately for $S$. eriocephala, $F_{1}$ hybrids, and backcrosses to $S$. eriocephala with the Spearman rank correlation. The relationship between aphid survival and mite gall presence on the same plant was tested separately for each genetic class with the Spearman rank correlation.

Genetic analyses: The additive and nonadditive genetic differences in aphid and mite resistance between $S$. eriocephala and $S$. sericea were evaluated with line cross analysis (Lynch and Walsh, 1998). This analysis assumes that $S$. eriocephala and $S$. sericea are completely homozygous for alleles that control resistance. It tests the extent to which additive, dominance, and epistatic interactions explain the deviation of mean resistance of $S$. eriocephala and $S$. sericea from a theoretical mean resistance of a population that is randomly crossed for an infinite number of generations (such that the population has all alleles from both species segregating and assorting randomly).

Since we had six genetic classes, we could potentially test for significance of five genetic composite effects (additive $(\alpha)$, dominance $(\delta)$, additive $\times$ additive epistasis $(\alpha \alpha)$, additive $\times$ dominance epistasis $(\alpha \delta)$, dominance $\times$ dominance epistasis $(\delta \delta)$ ) on resistance to aphids and mites. A composite effect is the sum of the additive, dominance, or epistatic effects over all loci. An additive composite effect $(\alpha)$ reveals a net difference between the two parental species in the additive effects of their genes. The dominance composite effect $(\delta)$ reveals whether genes in one parental species are dominant on average over genes in the other parental species. Epistatic composite effects $(\alpha \alpha, \alpha \delta, \delta \delta)$ reveal net epistatic interactions between genes from the two parental species.

For estimation of five genetic composite effects, there are 32 possible linear models of the following form:

$$
\begin{aligned}
\bar{Y}_{i}= & m+x_{\alpha}(\alpha)+x_{\delta}(\delta)+x_{\alpha \alpha}(\alpha \alpha)+x_{\alpha \delta}(\alpha \delta)+x_{\delta \delta}(\delta \delta) \\
& +e_{i}
\end{aligned}
$$

where $\bar{Y}_{i}$ is the mean of the $i$ th genetic class (parental species or hybrid), $(\alpha),(\delta),(\alpha \alpha),(\alpha \delta)$, and $(\delta \delta)$ are the various genetic composite effects, $x_{\alpha}, x_{\delta}, x_{\alpha \alpha}, x_{\alpha \delta}$, and $x_{\delta \delta}$ are the regression coefficients, and $e_{i}$ is the residual error. We used the regression coefficients outlined in Table 1 of Gilchrist and Partridge (1999), which are based on the expected mean of $F_{\infty}$ offspring as the intercept. This allows for the mean in linear models to represent the mean after numerous generations of inbreeding. Composite effects were estimated using a S-Plus ${ }^{\mathbb{R}}$ program that used a weighted least-squares model (Lynch and Walsh, 1998; Insightful Corp., 2001).

Goodness of fit to linear models was tested using the weighted residual sums of squares $\left(\mathrm{RSS}_{\mathrm{w}}\right)$ :

$$
\mathrm{RSS}_{w}=\sum_{i=1}^{k} \frac{e_{i}^{2}}{\mathrm{SE}_{i}^{2}}
$$

where $k$ is the number of crosses (6), $e_{i}^{2}$ is the difference between the observed and predicted ith composite genetic effect $(i=\alpha, \delta, \alpha \alpha, \alpha \delta$, or $\delta \delta)$, and $\mathrm{SE}_{i}^{2}$ is the standard error of the $i$ th estimated composite genetic effect (Lynch and Walsh, 1998; Bradshaw and Holzapfel, 2000; Bieri and Kawecki, 2003). RSS $_{\mathrm{w}}$ is $\chi^{2}$ distributed if data are normally distributed (degrees of freedom $=k-$ number of parameters in model); if significant, the model is inadequate to explain the observed means of the crosses.

Joint-scaling techniques are commonly used to sequentially add parameters into the model (first additive effects are added, then dominance, and then epistasis) until predicted and observed means do not significantly differ (Mather and Jinks, 1982; Bradshaw and Holzapfel, 2000). Yet, the order in which parameters are added into the model affects the ability to detect significant parameters that are added later. In addition, regression models with numerous parameters tend to produce less exact parameter estimates than models that contain only parameters explaining most of the variance (Bieri and Kawecki, 2003). For these reasons, we used Akaike's Information Criterion (AIC) to find the most parsimonious model, which is the best compromise between the amount of variance explained and the number of parameters in the model. Bieri and Kawecki (2003) show that $\mathrm{AIC}=\mathrm{RSS}_{\mathrm{w}}+2 \mathrm{~K}+$ constant, where $K$ is the number of parameters fitted into the model and the constant is the same for all models and can be dropped when comparing AIC scores among models. The model with the lowest AIC score is the most parsimonious.

It is possible that the most parsimonious model contains parameters that, if removed, do not significantly decrease the fit of the model to the observed genetic class means. A likelihood ratio test was thus used to test whether the removal of individual parameters significantly reduced the fit of the model (Lynch and Walsh, 1998). The degree of reduced fit of the model is estimated

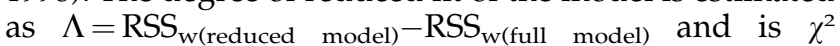
distributed at large sample sizes (degrees of free$\mathrm{dom}=$ number of parameters in full model-number of parameters in reduced model).

To compare composite genetic effects between replicates of the aphid-resistance experiment, we calculated the Wald $\chi^{2}$ statistic in which $\chi^{2}=\left(\beta_{1}-\beta_{2}\right)^{2} /\left(\operatorname{SE}\left(\beta_{1}\right)^{2}+\right.$ $\left.\operatorname{SE}\left(\beta_{2}\right)^{2}\right)$, where $\beta_{1}$ and $\beta_{2}$ are the composite genetic effects from each replicate and $\operatorname{SE}\left(\beta_{1}\right)$ and $\operatorname{SE}\left(\beta_{2}\right)$ are the standard errors of those composite genetic effects (Allison, 1995). The sum of the Wald $\chi^{2}$ provides a test of whether two models are different and is $\chi^{2}$ distributed with $k$ degrees of freedom ( $k=$ number of parameters in each model). Models with the same parameters were compared because the parameter estimates are sensitive to which parameters are included in the model (Allison, 1995). Since mean aphid survival differed between replicates (see Results), we did not include the overall mean when calculating the sum of the Wald $\chi^{2}$.

Since the assumption of normality is not met in the data and the sample size is small (ie, four, five, or six families within each genetic class, with large standard errors for some genetic classes), we note that the results of line cross analysis should be interpreted with caution.

\section{Results}

\section{Willow resistance to aphids}

Aphid survival: Average aphid survival on willows varied among the willow genetic classes (Figure 1; replicate $1: \mathrm{F}_{5,26}=2.99, P=0.029$; replicate $2: \mathrm{F}_{5,26}=8.31$, $P<0.001)$. The mean aphid survival on $S$. eriocephala plants was $78 \%$ lower than on $S$. sericea plants in replicate 1 and $94 \%$ lower in replicate 2 (Figure 1; replicate 1: $S$. 

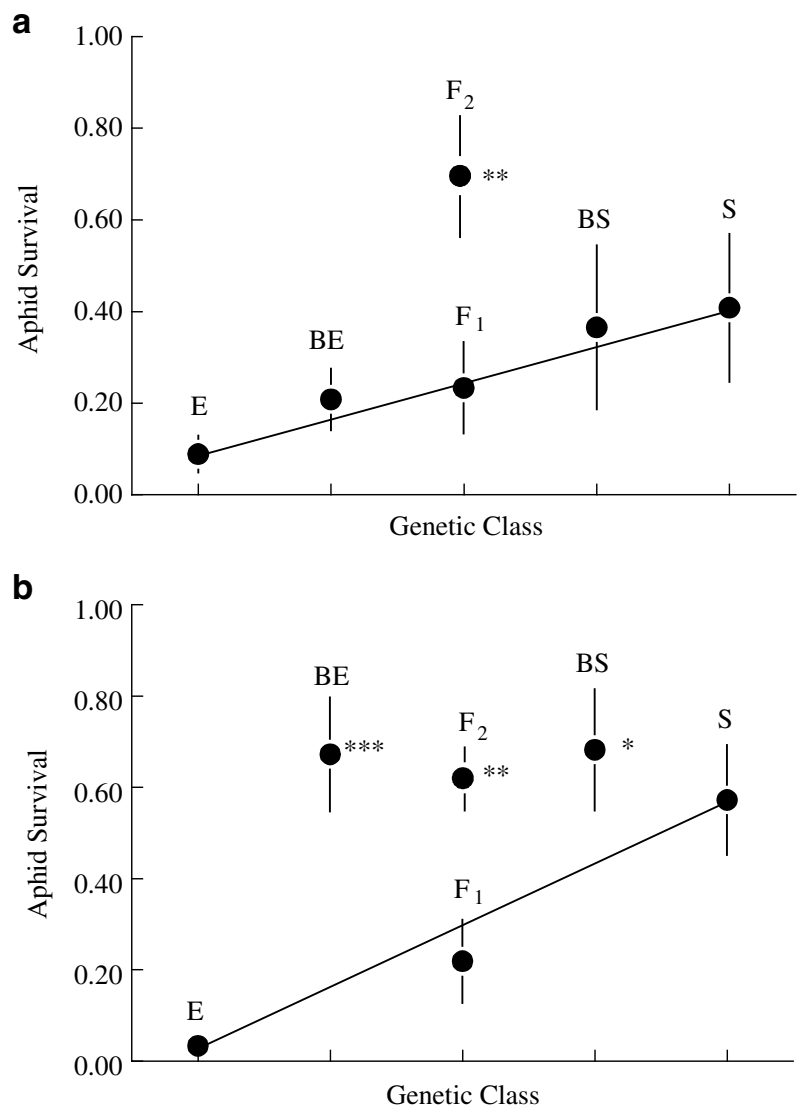

Figure 1 Mean survival of Chaitophorus sp. aphids $( \pm S E)$ on $S$. eriocephala (E), S. sericea (S), and their interspecific hybrids $\left(F_{1}, F_{2}\right.$, backcross to $S$. eriocephala (BE), and backcross to $S$. sericea (BS)) for two replicates (a and $\mathbf{b}$ ). Line connecting mean aphid survival on $\mathrm{E}$ and $S$ represents where means should fall if additive effects alone explained variation in resistance to aphids. Significantly different from line of additivity at ${ }^{*} P<0.05,{ }^{* * P} P<0.01$, ${ }^{* * *} P<0.001$ (significance tests used ranked data). eriocephala and $S$. sericea significantly different at $\mathrm{F}_{1,26}=4.30, P=0.029$; replicate $2: \mathrm{F}_{1,26}=16.49, P<0.001$ ).

There was a strong additive component to the inheritance of willow resistance to aphids - mean aphid survival on $F_{1}$ hybrids did not differ from an intermediate value between the $S$. eriocephala mean and $S$. sericea mean for both replicates (Figure 1a and b; replicate 1: $\quad \mathrm{F}_{1,26}=0.09, \quad P=0.767 ; \quad$ replicate $2: \mathrm{F}_{1,26}=0.75$, $P=0.393)$. Nonadditive genetic effects were also important in explaining the difference between parental species in resistance to aphids - mean aphid survival on the $F_{2}$ hybrids were much higher than predicted from a purely additive model of inheritance for both replicates (Figure $1 \mathrm{a}$ and $\mathrm{b}$; replicate $1: \mathrm{F}_{1,26}=9.56, P=0.005$; replicate $\left.2: F_{1,26}=8.55, P=0.007\right)$. Additionally, the $F_{2}$ mean did not differ from the $S$. sericea mean (Figure $1 \mathrm{a}$ and $\mathrm{b}$; replicate $1: \mathrm{F}_{1,26}=3.17, P=0.087$; replicate 2: $\left.\mathrm{F}_{1,26}=0.15, P=0.700\right)$. The results for the backcrosses differed between replicates (Figure $1 \mathrm{a}$ and $\mathrm{b}$ ). The mean aphid survival on both backcrosses in replicate 1 did not differ from an intermediate value between the predicted $F_{1}$ mean and either the $S$. eriocephala mean (for backcrosses to $S$. eriocephala; $\mathrm{F}_{1,26}=0.32, P=0.577$ ) or the $S$. sericea mean (for backcrosses to $S$. sericea; $\mathrm{F}_{1,26}=0.05, P=0.817$; Figure 1a). However, backcross means in replicate 2 did not support a purely additive model of inheritance (Figure 1b; backcrosses to $S$. eriocephala differed from predicted mean: $\mathrm{F}_{1,26}=23.29$, $P<0.001$; backcrosses to $S$. sericea; $\mathrm{F}_{1,26}=4.80, P=0.038$ ). Additionally, backcross means did not differ from the $S$. sericea mean (Figure 1b; backcrosses to $S$. eriocephala: $\mathrm{F}_{1,26}=0.56, \quad P=0.459 ; \quad$ backcrosses to $S$. sericea; $\left.\mathrm{F}_{1,26}=0.55, P=0.467\right)$.

The most parsimonious AIC model for replicate 1 included additive $\left(\alpha_{1}\right)$, dominance $\left(\delta_{1}\right)$, additive $\times$ additive epistatic $\left(\alpha^{2}\right)$, and dominance $\times$ dominance epistatic parameters $\left(\delta^{2}\right.$, although dominance $\times$ dominance epistasis could be dropped without significantly reducing the fit of the model to the data; Table 1). The most parsimonious AIC model for replicate 2 included these

Table 1 Composite genetic effects contributing to differences between S. eriocephala and S. sericea in mean survival and reproduction of Chaitophorus sp. aphids and mean total number of A. tetanothrix mite galls

\begin{tabular}{|c|c|c|c|c|c|c|}
\hline & \multicolumn{6}{|c|}{ Composite Effects (mean $\pm S E$ ) } \\
\hline & $\mu_{0}$ & $\alpha_{1}$ & $\delta_{1}$ & $\alpha^{2}$ & $\alpha \delta$ & $\delta^{2}$ \\
\hline \multicolumn{7}{|l|}{$\begin{array}{l}\text { Aphid } \\
\text { survival }\end{array}$} \\
\hline Replicate 1 & $\begin{array}{c}1.90 \pm 0.59 \\
\chi_{5}^{2}=0.0002\end{array}$ & $-0.16 \pm 0.08$ & $-3.13 \pm 1.32$ & $-1.65 \pm 0.60$ & - & $1.46 \pm 0.77^{a}$ \\
\hline Replicate 2 & $\begin{array}{c}0.28 \pm 0.06 \\
\chi_{4}^{2}=2.1031\end{array}$ & $-0.24 \pm 0.06$ & $1.52 \pm 0.28$ & - & - & $-1.58 \pm 0.29$ \\
\hline $\begin{array}{l}\text { Aphid } \\
\text { reproduction }\end{array}$ & $\begin{array}{c}19.4 \pm 2.8 \\
\chi_{3}^{2}=1.6648\end{array}$ & $-14.0 \pm 3.7$ & - & - & $62.9 \pm 17.5$ & - \\
\hline Total number of mite galls & $\begin{array}{c}-18.5 \pm 5.6 \\
\chi_{4}^{2}=0.3022\end{array}$ & $20.4 \pm 3.9$ & $40.7 \pm 10.6$ & $40.0 \pm 8.5$ & - & - \\
\hline
\end{tabular}

Aphid survival was analysed for two replicates. Composite genetic effects were estimated from the most parsimonious genetic model using Akaike's Information Criterion (AIC).

Model parameters: $\mu_{0}$, overall mean; $\alpha_{1}$, additive; $\delta_{1}$, dominance; $\alpha^{2}$, additive-additive epistasis; $\alpha \delta$, additive-dominance epistasis; $\delta^{2}$, dominance-dominance epistasis; a lower $\chi^{2}$ statistic indicates a better fit of the model to the data.

- Indicates a term that is not included in the AIC most parsimonious model.

${ }^{a}$ A composite effect in the AIC most parsimonious model that does not significantly reduce the fit of the model when dropped. 
parameters except additive $\times$ additive epistasis (Table 1 ). The magnitude of most parameters differed between replicates (for dominance: Wald $\chi_{1}^{2}=8.72, P=0.003$; for additive $\times$ additive epistasis: Wald $\chi_{1}^{2}=6.48, P=0.011$; for dominance $\times$ dominance epistasis: Wald $\chi_{1}^{2}=9.67$, $P=0.002$; additive parameter did not significantly differ between replicates: Wald $\chi_{1}^{2}=0.75, P=0.388$ ).

Aphid reproduction: Overall, there was a not a significant effect of willow genetic class on the total number of aphid offspring produced in a 2-week period (Figure 2; $F_{5,21}=1.82, P=0.152$ ). This result was similar when controlling for plant size $\left(\mathrm{F}_{5,21}<2.67, P>0.051\right.$ for total number of aphids per unit of plant height, leaf length, and leaf width). The mean aphid reproduction on $S$. eriocephala differed from that on $S$. sericea plants (Figure $2 ; \mathrm{F}_{1,21}=5.83, P=0.025$ ). All hybrid genetic class means did not differ from predicted means (Figure 2; $\mathrm{F}_{1,21}<1.097, P>0.175$; similar result after controlling for plant size). The most parsimonious AIC model included additive and additive $\times$ dominance epistatic effects on the difference in aphid reproduction between the two parental species (Table 1).

\section{Willow resistance to mites}

The total number of mite galls on a plant varied among the willow genetic classes (Figure 3; $\mathrm{F}_{5,29}=15.89$, $P<0.001)$. This result was similar when controlling for plant size $\left(\mathrm{F}_{5,27}>7.05, P<0.001\right.$ for total number of mite galls per unit of plant height, leaf length, and leaf width). The mean total number of galls on $S$. sericea plants was $97 \%$ lower than the mean total number of galls on $S$. eriocephala plants (Figure 3; S. eriocephala and S. sericea significantly different at $\left.F_{1,29}=47.43, P<0.001\right)$. The total number of galls on $F_{1}$ hybrids differed from an intermediate value between the parental species means $\left(F_{1,29}=5.47, P=0.027\right)$ and did not differ from the mean on $S$. eriocephala plants $\left(F_{1,29}=1.73, P=0.198\right)$. On $F_{2}$ hybrids, the mean total number of galls also differed from an intermediate value between the parental species means $\left(\mathrm{F}_{1,29}=6.15, P=0.019\right)$ and did not differ from the

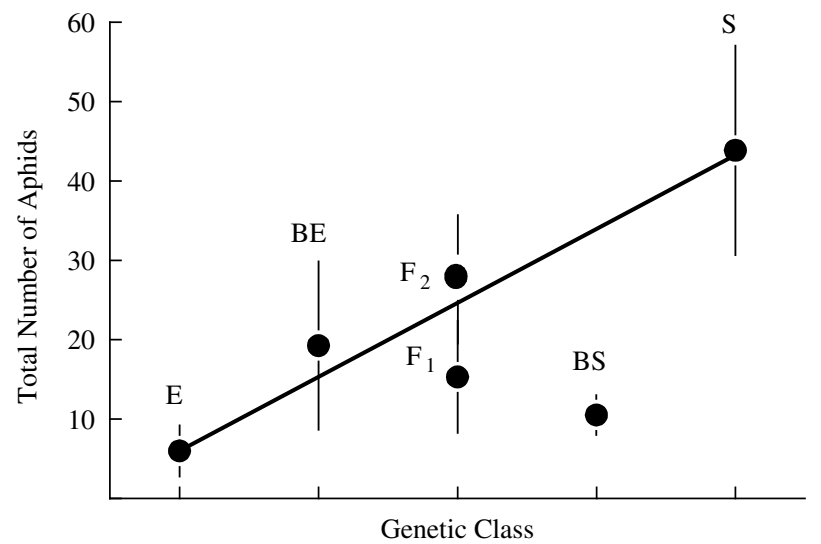

Figure 2 Mean number of Chaitophorus sp. aphids $( \pm S E)$ on $S$. eriocephala (E), S. sericea (S), and their interspecific hybrids $\left(\mathrm{F}_{1}, \mathrm{~F}_{2}\right.$, backcross to $S$. eriocephala (BE), and backcross to $S$. sericea (BS)). Line connecting mean number of aphids on $\mathrm{E}$ and $\mathrm{S}$ represents where means should fall if additive effects alone explained variation in resistance to aphids. No hybrid mean significantly differed from line of additivity $(P>0.175$; significance tests used ranked data).

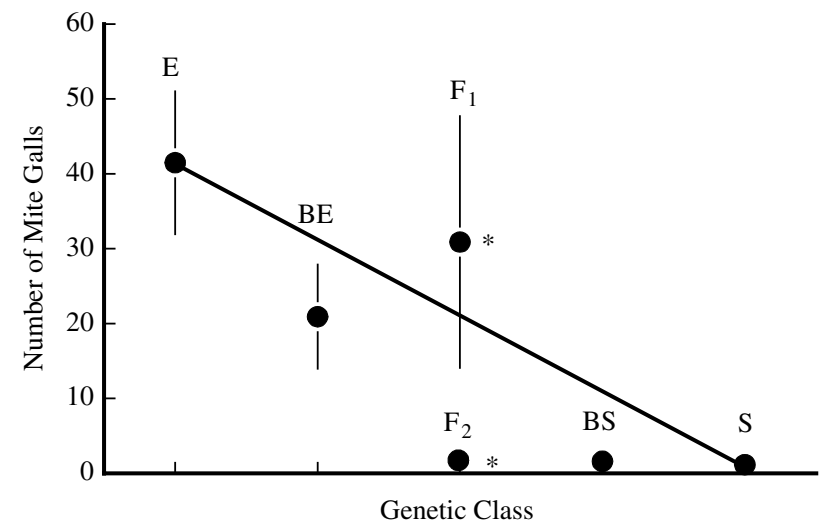

Figure 3 Mean total number of $A$. tetanothrix mite galls $( \pm S E)$ on Salix eriocephala (E), S. sericea (S), and their interspecific hybrids $\left(F_{1}\right.$, $\mathrm{F}_{2}$, backcross to $S$. eriocephala (BE), and backcross to S. sericea (BS)). Line connecting mean number of galls on $\mathrm{E}$ and $\mathrm{S}$ represents where means should fall if additive effects alone explained variation in resistance to mites. * Significantly different from line of additivity at $P<0.05$ (significance tests used ranked data).

mean on $S$. sericea plants $\left(\mathrm{F}_{1,29}=1.54, P=0.225\right)$. The most parsimonious AIC model included additive, dominance, and additive $\times$ additive epistatic interaction effects for explaining the difference between parental species in resistance to mites (Table 1).

The type of gall, large or small, did not differ among willow genetic classes - the proportion of large galls on a plant was not affected by the willow genetic class (but note marginal significance; $\mathrm{F}_{5,25}=2.54, P=0.054$ ). Larger galls contained more mites and eggs than smaller galls (on S. eriocephala: $r=0.36, P<0.001$; on $\mathrm{F}_{1}$ hybrids: $r=0.48, \quad P<0.001$; on backcrosses to $S$. eriocephala: $r=0.42, P=0.018$; mites within galls on the other genetic classes were not counted due to the extremely low number of galls on these plants, see Figure 3).

\section{Relationship between aphid and mite resistance}

In most genetic classes, there was no relationship between aphid survival and the presence of mite galls on the same plant $(|r|<0.63, P>0.178)$. In genetic classes where a significant relationship was detected, it was only detected within one of the replicates $(r=-0.82$, $P=0.045$ for $S$. eriocephala in replicate 1 , but $r=-0.63$, $P=0.178$ in replicate $2 ; r=-0.89, P=0.016$ for backcrosses to $S$. eriocephala in replicate 2, but $r=-0.09$, $P=0.860$ in replicate 1$)$.

\section{Discussion}

Selection may act on combinations of genes within or across loci that interact with each other to produce a particular resistant phenotype. Hybridisation can disrupt such gene combinations, and the hybrid fitness that results depends on a balance between the loss of favourable and the loss of unfavourable interactions within the parental genomes (Arnold, 1997). In this study, resistance to aphids was much lower than predicted from a purely additive model of inheritance for some recombinant hybrids, suggesting breakdown of favourable gene interactions in the $S$. eriocephala genome that confer resistance to aphids (measured as aphid survival; Figure 1a and b). Alternatively, low resistance 
of hybrids can be explained by the creation of unfavourable gene interactions or underdominance (Schierup and Christiansen, 1996).

An opposite pattern was observed for mite resistance $\mathrm{F}_{2}$ hybrids were more resistant than predicted from a purely additive model of resistance (Figure 3). Perhaps a disruption of gene interactions has occurred within the $S$. eriocephala genome that affect traits used by mites to locate suitable host plants (Fritz et al, 2003). Alternatively, favourable interactions that confer resistance to mites may be expressed in these $\mathrm{F}_{2}$ hybrids.

The number of generations required for appearance of hybrid breakdown of gene interactions depends on the degree of linkage among genes and on the number of genes involved (Templeton, 1986; Edmands, 1999). It has been documented that hybrid fitness often decreases as quickly as the $F_{2}$ generation. For example, heterosis for fitness components was detected in $F_{1}$ hybrids of interpopulational crosses of the copepod Tigriopus californicus, while $\mathrm{F}_{2}$ hybrids exhibited hybrid breakdown in fitness components (ie, number of hatchlings, number of metamorphosed juveniles, and number of surviving hatchlings and juveniles, Edmands, 1999). The same pattern was observed for the legume Chamaecrista fasciculata - heterosis was observed in $\mathrm{F}_{1}$ hybrids, while hybrid breakdown was observed in the $\mathrm{F}_{3}$ generation (for germination rate, vegetative biomass, and fruit production, Fenster and Galloway, 2000). In this study, $\mathrm{F}_{1}$ hybrid resistance to aphids, in terms of aphid survival, did not differ significantly from an intermediate value between the parental means, but $F_{2}$ hybrid resistance was low, suggesting hybrid breakdown of favourable gene interactions (Table 1).

Hybrid resistance to different herbivores may vary from that of the parental species such that unique combinations of herbivores are present on hybrids that are not present on the parental species (Dungey et al, 2000; Wimp and Whitham, 2001). This has been found previously for some herbivores in this study system. For example, decreased hybrid resistance relative to both parental species was observed for the leaf miners Phyllonorycter salicifoliella and Phyllocnistis sp., the leaf galling sawfly Phyllocolpa terminalis, the leaf galling fly Iteomyia sp., and Melampsora rust (for $\mathrm{F}_{1}$ and backcrosses, see Fritz et al, 1994). In this study, depending on the hybrid class, hybrids can support both aphid and mite populations, while each parental species is highly resistant to either one herbivore or the other.

Plants are often attacked by numerous herbivorous and pathogenic species, and resistance to one species may not be effective against another species (Agrawal et al, 1999; Strauss et al, 2002). For the hybrid willow genetic classes in this study, there was not a significant relationship between aphid survival and the presence of mite galls on the same plant. This indicates a lack of a trade-off between aphid and mite resistance within the hybrid classes, which suggests that the traits that confer resistance to aphids do not draw upon the same pool of resources as traits that confer resistance to mites.

To better understand the processes genetic differentiation, local adaptation and speciation in general, more studies of genetic architecture of fitness traits are needed in natural hybrid systems. Here, we have studied the genetic architecture of willow resistance to two arthropod herbivores, likely an important component of plant fitness, and have found that the difference in mean resistance to aphids and mites between the two willow species is attributed to additive and nonadditive genetic effects. Detection of significant additive and/or nonadditive genetic effects aids in our understanding of how populations and/or species have become genetically diverged (Wolf et al, 2000). The two willow species in this study are sympatric in much of their geographic range and naturally hybridise with each other, yet exhibit high resistance to either one herbivore or the other. Hybridisation leads to the breakdown of gene interactions that potentially affect host plant resistance or host recognition by herbivores.

\section{Acknowledgements}

This work was funded by grant numbers BSR 96-15038, DEB 99-81406, and DEB 01-08172 from the National Science Foundation. We thank L and E Sosnowski and M Membrino for use of their land during these experiments. We also thank C Fox and two anonymous reviewers for providing helpful comments on this manuscript. C Rauter provided the S-Plus ${ }^{\mathbb{R}}$ program used for line cross analysis (modified by MEC). Aphids were identified by the Communications and Taxonomic Services Unit of the USDA Systematic Entomology Laboratory.

\section{References}

Agrawal AA, Gorski PM, Tallamy DW (1999). Polymorphism in plant defense against herbivory: constitutive and induced resistance in Cucumis sativus. J Chem Ecol 25: 2285-2304.

Allison PD (1995). Survival Analysis Using the SAS System: a Practical Guide. SAS Institute Inc: Cary, North Carolina, USA.

Argus GW (1974). An experimental study of hybridization and pollination in Salix (willow). Can J Bot 52: 1613-1619.

Argus GW (1986). The genus Salix (Salicaceae) in the southeastern United States. Syst Bot Monogr 9: 1-170.

Armbruster P, Bradshaw WE, Holzapfel CM (1997). Evolution of the genetic architecture underlying fitness in the pitcherplant mosquito, Wyoemyia smithii. Evolution 51: 451-458.

Arnold ML (1997). Natural Hybridization and Evolution. Oxford University Press: New York, New York, USA.

Arnold ML, Hodges SA (1995). Are natural hybrids fit or unfit relative to their parents? Trends Ecol Evol 10: 67-71.

Bieri J, Kawecki TJ (2003). Genetic architecture of differences between populations of cowpea weevil (Callosobruchus maculatus) evolved in the same environment. Evolution 57: 274-287.

Bradshaw WE, Holzapfel CM (2000). The evolution of genetic architecture and the divergence of natural populations. In Wolf JB, Brodie III ED, Wade MJ (eds) Epistasis and the Evolutionary Process. Oxford University Press: New York, New York, USA, pp 245-263.

Burke JM, Arnold ML (2001). Genetics and the fitness of hybrids. Annu Rev Genet 35: 31-52.

Dixon AFG (1985). Aphid Ecology. Chapman and Hall: New York, New York, USA.

Dungey HS, Potts BM, Whitham TG, Li HF (2000). Plant genetics affects arthropod community richness and composition: evidence from a synthetic eucalypt hybrid population. Evolution 54: 1938-1946.

Edmands S (1999). Heterosis and outbreeding depression in interpopulation crosses spanning a wide range of divergence. Evolution 53: 1757-1768.

Fenster CB, Galloway LF (2000). Population differentiation in an annual legume: genetic architecture. Evolution 54: 1157-1172. 
Fritz RS (1999). Resistance of hybrid plants to herbivores: genes, environment, or both? Ecology 80: 382-391.

Fritz RS, Hochwender CG, Brunsfeld SJ, Roche BM (2003). Genetic architecture of susceptibility to herbivores in hybrid willows. J Evol Biol 16: 1115-1126.

Fritz RS, Moulia C, Newcombe G (1999). Resistance of hybrid plants and animals to herbivores, pathogens, and parasites. Annu Rev Ecol Syst 30: 565-591.

Fritz RS, Nichols-Orians CM, Brunsfeld SJ (1994). Interspecific hybridization of plants and resistance to herbivores: hypotheses, genetics, and variable responses in a diverse herbivore community. Oecologia 97: 106-117.

Galloway LF, Fenster CB (2001). Nuclear and cytoplasmic contributions to intraspecific divergence in an annual legume. Evolution 55: 488-497.

Gilchrist AS, Partridge L (1999). A comparison of the genetic basis of wing size divergence in three parallel body size clines of Drosophila melanogaster. Genetics 153: 1775-1787.

Hardig TM, Brunsfeld SJ, Fritz RS, Morgan M, Orians CM (2000). Morphological and molecular evidence for hybridization and introgression in a willow (Salix) hybrid zone. Mol Ecol 9: 9-24.

Insightful Corp (2001). S-Plus for Windows User's Guide. Seattle, Washington, USA.

Linder CR, Taha I, Seiler GJ, Snow AA, Rieseberg LH (1998) Long-term introgression of crop genes into wild sunflower populations. Theor Appl Genet 96: 339-347.

Lynch M (1991). The genetic interpretation of inbreeding depression and outbreeding depression. Evolution 45: 622-629.

Lynch M, Walsh B (1998). Genetics and the Analysis of Quantitative Traits. Sinauer Associates Inc.: Sunderland, Massachusetts, USA.

Manson DCM, Oldfield GN (1996). Life forms, deuterogyny, diapause and seasonal development. In: Lindquist EE, Sabelis MW, Bruin J (eds) Eriophyoid Mites - Their Biology Natural Enemies and Control. Elsevier Science BV: Amsterdam, The Netherlands, pp 173-183.
Mather K, Jinks JL (1982). Biometrical Genetics: the Study of Continuous Variation. Chapman and Hall: London, England.

Merilä J, Sheldon BC (1999). Genetic architecture of fitness and nonfitness traits: empirical patterns and development of ideas. Heredity 83: 103-109.

Mosseler A, Papadopol CS (1989). Seasonal isolation a reproductive barrier among sympatric Salix species. Can J Bot 67: 2563-2570.

Orians CM, Fritz RS (1995). Secondary chemistry of hybrid and parental willows: Phenolic glycosides and condensed tannins in Salix sericea, S. eriocephala, and their hybrids. J Chem Ecol 21: 1245-1253.

Rieseberg LH (1997). Hybrid origins of plant species. Annu Rev Ecol Syst 28: 359-389.

SAS Institute Inc. (1985). SAS User's Guide: Statistics. Ver 8, 5th edn. Cary, North Carolina, USA.

Schierup MH, Christiansen FB (1996). Inbreeding depression and outbreeding depression in plants. Heredity 77: 461-468.

Strauss SY, Rudgers JA, Lau JA, Irwin RE (2002). Direct and ecological costs of resistance to herbivory. Trends Ecol Evol 17: 278-285.

Templeton AR (1986). Coadaptation and outbreeding depression. In: Soule ME (ed) Conservation Biology: the Science of Scarcity and Diversity. Sinauer Associates Inc.: Sunderland, Massachusetts, USA, pp 105-116.

Waser NM (1993). Population structure, optimal outbreeding, and assortative mating in angiosperms. In: Thornhill NW (ed) Natural History of Inbreeding and Outbreeding. The University of Chicago Press: Chicago, Illinois, USA, pp 173-199.

Whitham TG (1989). Plant hybrid zones as sinks for pests. Science 244: 1490-1493.

Wimp GM, Whitham TG (2001). Biodiversity consequences of predation and host plant hybridization on an aphid-ant mutualism. Ecology 82: 440-452.

Wolf JB, Brodie III ED, Wade MJ (2000). Epistasis and the Evolutionary Process. Oxford University Press: New York, New York, USA. 